\title{
EXTRACTION OF MONOMERS OF HYDROLYSABLE TANNINS FROM PODS OF Libidibia ferrea (Mart. ex Tul.) L. P. QUEIROZ: EFFECTS OF SOLVENT AND AMOUNT OF DRUG USING RESPONSE-SURFACE METHODOLOGY AND DESIRABILITY PROFILE
}

\author{
Magda R. A. Ferreiraa,*,i), Patricia A. Sousa ${ }^{a}$, Janaína C. B. Machado ${ }^{a}$ and Luiz A. L. Soares ${ }^{\mathrm{a}}$ \\ aDepartamento de Ciências Farmacêuticas, Universidade Federal de Pernambuco, 50740-521 Recife - PE, Brasil
}

Recebido em 17/01/2020; aceito em 11/03/2020; publicado na web em 24/04/2020

\begin{abstract}
In this study was evaluated the influence of the extraction factors on the extract's properties to improve the recovery of high concentrations of the phytochemicals important for the biological activities from pods of Libidibia ferrea (Mart. ex Tul.) L. P. Queiroz. The extracts were obtained by turbo-extraction and a factorial design $3^{2}$ was used to study the importance of the drug amount $(5,10$ or $15 \mathrm{~g}$ ) and the solvent (Ethanol 40, 60 or 80\%, v/v) on the variables of response, and the optimization was performed by Response Surface Methodology (RSM) and Desirability profile. Mathematical models were fitted according to experimental data and the validated equations were used to generate RSM for each dependent variable (dry residue; total polyphenol content; content of gallic acid and ellagic acid; and, efficiency of extraction). The factors studied within the applied experimental field presented different influence profiles for the responses, and significant interactions between linear and quadratic terms. The statistical analysis showed high $R^{2}>0.99$. The RSM and Desirability ( $>0.95$ ) allowed to show that the optimum conditions to produce extractive solutions of Libidibia ferrea with high efficiency for ellagic acid and gallic acid were $15 \mathrm{~g}$ and ethanol $40 \%$.
\end{abstract}

Keywords: Libidibia ferrea; Response Surface Methodology; Desirability; optimization.

\section{INTRODUCTION}

Libidibia ferrea (Mart. ex Tul.) L. P. Queiroz var. ferrea (Fabaceae) is a native species of Brazil, with distribution in the Northeast and Southeast. ${ }^{1}$ It is known as "jucá" or "pau ferro", and its pharmacogens are used in traditional medicine to treat diarrhea, diabetes and anemia. ${ }^{2,3}$ In addition to reports of traditional medicine, biological activities have been described in the literature. The barks have antifungal activity, ${ }^{4}$ antimicrobial, analgesic and anti-inflammatory; ${ }^{5}$ the pods have antiproliferative, apoptotic and antioxidant activities, ${ }^{6}$ anti-inflammatory and antinociceptive $;{ }^{7}$ and the leaves decreased intra-articular inflammation. ${ }^{8}$

Studies related to the chemical constitution of the species reported the presence of a wide variety of polyphenols, ${ }^{9}$ such as: bark condensed tannins ${ }^{5}$ and hydrolysable fruits ${ }^{10}$ and leaves $;{ }^{8}$ besides flavonoids, coumarins, terpenoids, steroids, saponins and polysaccharides. $^{3}$

The popular use, biological activities and chemical composition of the fruits, associated with the scarcity of data related to the production of $L$. ferrea extracts demonstrate the relevance of evaluating and standardizing extractive solutions, representing an important step towards obtaining a product that meets requirements set by regulatory agencies. Thus, it is important to evaluate extractive methods, solvents, drug proportion, as well as the influence on the marker content and the physicochemical properties of the extractive solutions to ensure reproducibility and quality of the obtained products. ${ }^{11-15}$ These effects can be measured through factorial assays, which allow the evaluation of two or more factors, also allowing the measurement of joint effects, determining possible compatibilities and incompatibilities. ${ }^{16,17}$

The effect of extraction parameters, such as solvent and amount of drug on dry residue, total polyphenol content (TPC) and content of markers from Libidibia ferrea pods has not been studied and will therefore be evaluated in the present work, using Response Surface

*e-mail: magda.ferreira00@gmail.com
Methodology and Desirability profile, in order to maximize the extraction of chemical markers important for the biological activities from pods of L. ferrea.

\section{EXPERIMENTAL}

\section{Herbal material}

The pods of Libidibia ferrea were collected in the city of Limoeiro (Pernambuco, Brazil). The plant material was identified, and voucher specimen was deposited at the Instituto Agronômico de Pernambuco (IPA-PE) under registration number 88145 . The access to the species was registered in the Sistema Nacional de Gestão do Patrimônio Genético e Conhecimento Tradicional Associado (SisGen) at the number AB56479. The material was drying in a circulating air oven (Luca-82-480, Lucadema ${ }^{\circledR}$ ) for $72 \mathrm{~h}$ under $40{ }^{\circ} \mathrm{C}$. After drying, the pods were ground in Willye-type knife mill (TE-680, Tecnal $^{\circledR}$ ).

\section{Optimization of extraction}

\section{Extractive solutions}

The extracts were obtained by turbo-extraction for 20 minutes, 4 cycles of 30 seconds with 5 minutes intervals. The extracts were filtered with cotton and filter paper by vacuum. ${ }^{18,19}$

\section{Factorial design $3^{2}$}

The proportions of the amount of drug $(5,10$ and $15 \mathrm{~g})$ and ethanol proportion (40,60 and $80 \%$ ) are performed by factorial design $3^{2}$. At the end, the extracts obtained were evaluated for dry residue; total polyphenols content by UV-Vis spectrophotometry and content of markers gallic acid (GA) and ellagic acid (EA) by high performance liquid chromatography (HPLC); and, efficiency of extraction. The model was validated using ANOVA with the Statistica ${ }^{\circledR}$ program (StatSoft, USA), according to the criteria proposed by Wherlé ${ }^{16}$ (Table 1). The results were expressed as mean and relative standard 
deviation; and were analyzed with the software Statistica ${ }^{\circledR}$ (Table 2). The data were studied using least squares multiple regression method, for the factorial design used as follows:

$y=b_{0}+b_{1} x_{1}+b_{2} x_{2}+b_{11}\left(x_{1}\right)^{2}+b_{22}\left(x_{2}\right)^{2}+b_{12} x_{1} x_{2}+b_{122} x_{1}\left(x_{2}\right)^{2}+$ $b_{112}\left(x_{1}\right)^{2} x_{2}+b_{1122}\left(x_{1}\right)^{2}\left(x_{2}\right)^{2}$

where: $y$ is the response (dry residue, total polyphenol content, extractive efficiency, ellagic acid content or gallic acid content), and $b_{0}$ to $b_{22}$ are the regression coefficients.

Table 1. Criteria adopted for validation of mathematical models

\begin{tabular}{cccc}
\hline ANOVA & $\mathrm{R}^{2}$ value & LOF & Validation \\
\hline $\mathrm{p}<0.05$ & $\mathrm{R}^{2}>0.9$ & - & Yes \\
$\mathrm{p}<0.05$ & $0.8<\mathrm{R}^{2}<0.9$ & $\mathrm{p}>0.05$ & Yes \\
$\mathrm{p}<0.05$ & $0.8<\mathrm{R}^{2}<0.9$ & $\mathrm{p}<0.05$ & No \\
$\mathrm{p}<0.05$ & $\mathrm{R}^{2}<0.8$ & - & No \\
$\mathrm{p}<0.05$ & - & - & No \\
\hline
\end{tabular}

LOF: Lack of fit.

\section{Determination of dry residue}

The dry residue (DR) was determined in infrared balance (Series-ID v. 18, Marte ${ }^{\circledR}$ ), using $5 \mathrm{~mL}$ of the extractive solution, at a temperature of $130 \pm 1{ }^{\circ} \mathrm{C}$ until mass variation does not changing for 30 seconds.

\section{Quantification of polyphenols by UV-Vis spectrophotometry}

The total polyphenol content was obtained according to the methodology described by Ferreira et al.,$^{10}$ with some adaptations. An aliquot of $0.5 \mathrm{~mL}$ from stock solution was then transferred to a $25 \mathrm{~mL}$ volumetric flask and the volume was completed with purified water (S1). Subsequently, an aliquot of $2 \mathrm{~mL}$ from $\mathrm{S} 1$ was transferred to a $25 \mathrm{~mL}$ volumetric flask, $2 \mathrm{~mL}$ of Folin-Ciocalteu and $10 \mathrm{~mL}$ of water were added, and the volume was filled with a solution of anhydrous sodium carbonate $\left(\mathrm{Na}_{2} \mathrm{CO}_{3}\right) 29 \%(\mathrm{w} / \mathrm{v})$. The samples were measured at $760 \mathrm{~nm}$ in an UV/Vis spectrophotometer (Thermo Scientific $\left.^{\circledR}\right)$ at 30 min after the addition of the last reagent. Water was used as the blank. Tests were carried out in triplicate. Pyrogallol was used as standard.

\section{Extractive efficiency}

The extractive efficiency (EE) was determined by the relation of the contents of the metabolites of interest (polyphenol, gallic acid or ellagic acid) to the solid content (dry residue) obtained for the extracts, according to the equation below. ${ }^{11}$

$$
E E=T C / D R
$$

where: $\mathrm{EE}=$ Extraction Efficiency; TC $=$ Total Content of markers (polyphenol; ellagic acid or gallic acid); DR = Dry residue.

\section{Quantification of markers by High Performance Liquid Chromatography (HPLC)}

The quantification of markers ellagic acid and gallic acid was performed according the methodology described by Ferreira et al. ${ }^{10}$ in an HPLC-Ultimate 3000 (Thermo Fisher Scientific ${ }^{\circledR}$ ). The wavelength was set at $254 \mathrm{~nm}$ for detection of the ellagic acid (EA) and $270 \mathrm{~nm}$ for gallic acid (GA). The chromatographic separations were achieved with a $\mathrm{C}_{18}$ column $(250 \mathrm{~mm} \times 4.6 \mathrm{~mm}$ i.d., particle size $5 \mu \mathrm{m})$ from Phenomenex ${ }^{\circledR}$ equipped with a guard column $\left(\mathrm{C}_{18}, 4 \mathrm{~mm} \times 3.9 \mu \mathrm{m}\right.$, Phenomenex ${ }^{\circledR}$ ) and were carried out at a column oven temperature of $25 \pm 1{ }^{\circ} \mathrm{C}$. The mobile phase consisted of purified water (A) and methanol (B), both acidified with $0.05 \%$ trifluoracetic acid (TFA), at a flow rate adjusted to $0.8 \mathrm{~mL} \mathrm{~min}^{-1}$. A gradient program was applied as follows: 0-10 $\mathrm{min}, 12.5-25 \% \mathrm{~B} ; 10-15 \mathrm{~min}, 25-40 \% \mathrm{~B}$; $15-25 \mathrm{~min}$, 40-75\% B; 25-30 min, 75-75\% B; 30-33 min, 75-12.5\% B.

Samples of $250 \mu \mathrm{L}$ of each extract were transferred to $25 \mathrm{~mL}$ volumetric flasks and the volume completed with ultrapure water (Purelab ${ }^{\circledR}$ Classic UV, ELGA LabWater, USA). The samples were then filtered through PVDF membrane $\left(0.45 \mu \mathrm{m}\right.$, Macherey-Nagel $\left.{ }^{\oplus}\right)$ directly into the vials. The results in contents were expressed as $\mathrm{g} \%$ of gallic acid (98\%) and ellagic acid (95\%), purchased from Sigma-Aldrich ${ }^{\circledR}$.

\section{RESULTS AND DISCUSSION}

In our investigation research we studied the extraction of gallic acid and ellagic acid and total polyphenol content from pods of Libidibia ferrea using classical optimization approach of $3^{2}$ experimental design and response surface methodology (RSM) to achieve maximum enriched extract. There are no reports in the literature related to the optimization of conditions for extraction

Table 2. Matrix of the factorial design $3^{2}$ for extractive solutions of L. ferrea pods

\begin{tabular}{|c|c|c|c|c|c|c|c|c|}
\hline \multicolumn{2}{|c|}{ Natural variables } & \multicolumn{7}{|c|}{ Responses } \\
\hline Drug (g) & $\mathrm{EtOH}(\%)$ & $\mathrm{DR}(\%)$ & $\mathrm{TPC}(\mathrm{g} \%)$ & EE (TPC/DR) & $\mathrm{GA}(\mathrm{g} \%)$ & $\mathrm{EA}(\mathrm{g} \%)$ & EE (GA/DR) & $\mathrm{EE}$ (EA/DR) \\
\hline 5 & 40 & $2.52(1.40)$ & $15.18(1.15)$ & $6.03(1.39)$ & $2.14(0.84)$ & $0.80(3.09)$ & $0.85(1.22)$ & $0.32(4.29)$ \\
\hline 5 & 60 & $2.71(2.81)$ & $23.69(0.30)$ & $8.74(3.14)$ & $2.42(3.30)$ & $1.34(1.16)$ & $0.90(2.90)$ & $0.34(3.82)$ \\
\hline 5 & 80 & $2.42(2.89)$ & $38.61(0.38)$ & $15.96(2.62)$ & $13.26(0.24)$ & $7.50(0.34)$ & $1.17(2.90)$ & $0.44(2.86)$ \\
\hline 10 & 40 & $5.82(3.48)$ & $19.61(0.07)$ & $3.37(3.45)$ & $2.45(0.22)$ & $0.92(1.01)$ & $0.42(3.92)$ & $0.23(2.58)$ \\
\hline 10 & 60 & $5.87(1.21)$ & $28.91(0.13)$ & $4.93(1.35)$ & $2.50(0.77)$ & $1.12(0.23)$ & $0.43(1.33)$ & $0.19(1.26)$ \\
\hline 10 & 80 & $4.22(1.79)$ & $40.89(0.34)$ & $9.68(1.74)$ & $7.68(0.95)$ & $3.99(1.97)$ & $0.48(1.67)$ & $0.26(2.14)$ \\
\hline 15 & 40 & $7.95(0.67)$ & $33.13(0.15)$ & $4.17(0.66)$ & $2.82(0.03)$ & 1.07 (0.09) & $1.67(0.43)$ & $0.94(0.94)$ \\
\hline 15 & 60 & $7.77(1.80)$ & $31.96(0.05)$ & $4.11(1.80)$ & $2.04(0.11)$ & $1.08(0.52)$ & $3.18(2.47)$ & 1.65 (1.79) \\
\hline 15 & 80 & 7.77 (5.94) & $45.32(0.61)$ & $5.84(3.14)$ & $5.41(0.72)$ & $2.21(0.54)$ & $0.70(4.83)$ & $0.29(4.63)$ \\
\hline
\end{tabular}

Run; EtOH: Ethanol; DR: dry residue; TPC: Total Polyphenol Content; EE: extractive efficiency; EA: Ellagic acid; GA: Gallic acid. The results were expressed as mean (relative standard deviation). 
of its constituents using RSM approach. Table 1 reports the results of ethanol concentration and amount of drug on the previously mentioned responses (DR, TPC, EE and markers content by HPLC) of Libidibia ferrea pods extract obtained by turbo-extraction on the factorial design.

The factors studied within the applied experimental field showed different influence profiles for the evaluated responses, and significant interactions between them, as well as between the linear and quadratic terms. The statistical analysis of the calculated mathematic models for the all responses variables displayed high coefficients of determinations $\left(R^{2}>0.99\right)$. The multiple correlation coefficients allowed concluding that the proposed equations could explain more than $99 \%$ of the experimental variability and, besides the adequate approximation of the fitted models (Table 3), no violations of the model assumptions occurred. ${ }^{16,17,20}$

The analysis of variance of the data showed high values of $F$ and low values of $p$, close to zero and $<5 \%$. These results indicate that the alternative hypothesis of regression significance is true and that the model is well adjusted.${ }^{17}$ Considering the lack of fit (LOF) test, which assesses the adequacy of the mathematical model to the phenomenon studied, the results obtained did not indicate a LOF for the models, thus, it is assumed that the variation is associated with random errors. This implies that tested quadratic model was adequate to explain the behavior of the responses (TPC, GA and EA content, and EE) to the factors (amount of drug and proportion of ethanol) evaluated.

The contribution of the second order model could be observed by the curvature of the response surface. So, that a convex form of the curve presents due to a negative influence on the quadratic response. The quadratic term demonstrates the contribution of the factor to the presence of curvature, which can be observed in the response surface graphs, indicating the nature of the system for maximum and minimum values under optimal conditions..$^{11,17}$

The study of RSMs generated by quadratic models reveals critical points of the experimental field that can characterize the nature of the surface system (maximum, minimum or saddle). The behavior is result of the contributions of the second order terms and describes the presence of curvatures. ${ }^{17}$ In this way, the saddle-shaped critical point is the inflection point between a maximum and a minimum. In Figure 1, there were no response surfaces with a saddle point, since, in this type of shape, the surface is concave in two directions, and is also called the minimax point. Therefore, since the objective is to obtain a maximum response for the studied system, the saddle point coordinates do not serve as ideal values, but it is possible to observe the response surface and find the best region. ${ }^{11,17,21}$

\section{Dry Residue, Total Polyphenol Content and Efficiency Extraction}

Regarding the influence of each factor, the linear term of Ethanol Concentration (\%) was found as the most significant process parameter on the Total Polyphenol content, followed by linear amount of drug $(p<0.0001)$. As for dry residue, ellagic acid and gallic acid contents, linear effect of amount of drug was found as the most important parameter. On the other hand, the factor Drug Amount (g) improve the yielding of soluble solids (dry residue) at the higher level, and both terms were significant. Meanwhile, the quadratic term of Ethanol (\%) showed negative influence on the response (Figure 1A).

With relation to the Total Polyphenols Content (TPC) of extractive solutions from pods of $L$. ferrea, our findings showed the positive contributions of the linear terms of both main factors (drug and ethanol). The solubility in the solvent explains the linear dependent of the TPC from drug amount (Figure 1B). The data suggest special attention to the standardization of operations, as well as the performance of each extractive method and its relationship to each plant species. Several studies are performed to select the best solvent to remove the largest amount of polyphenols in plant materials, however, the solvent system used depends greatly on the chemical and structural constitution of phenolic constituents. ${ }^{22}$

Table 3. Statistical analysis of the mathematical models from factorial design

\begin{tabular}{|c|c|c|c|c|c|c|c|c|c|c|c|c|c|c|}
\hline \multirow[b]{2}{*}{ Terms } & \multicolumn{2}{|c|}{$\mathrm{DR}(\mathrm{g} \%)$} & \multicolumn{2}{|c|}{$\mathrm{TPC}(\mathrm{g} \%)$} & \multicolumn{2}{|c|}{ EE (TPC/DR) } & \multicolumn{2}{|c|}{$\mathrm{GA}(\mathrm{g} \%)$} & \multicolumn{2}{|c|}{$\mathrm{EE}(\mathrm{GA} / \mathrm{DR})$} & \multicolumn{2}{|c|}{$\mathrm{EA}(\mathrm{g} \%)$} & \multicolumn{2}{|c|}{$\mathrm{EE}(\mathrm{EA} / \mathrm{DR})$} \\
\hline & $\begin{array}{c}\text { Coef. } \\
\text { ( } t \text {-test) }\end{array}$ & $F$-test & $\begin{array}{c}\text { Coef. } \\
\text { ( } t \text {-test) }\end{array}$ & $F$-test & $\begin{array}{c}\text { Coef. } \\
\text { (t-test) }\end{array}$ & $F$-test & $\begin{array}{c}\text { Coef. } \\
\text { (t-test) }\end{array}$ & $F$-test & $\begin{array}{l}\text { Coef. } \\
\text { ( } t \text {-test) }\end{array}$ & $F$-test & $\begin{array}{c}\text { Coef. } \\
\text { ( } t \text {-test) }\end{array}$ & $F$-test & $\begin{array}{c}\text { Coef. } \\
\text { ( } t \text {-test) }\end{array}$ & $F$-test \\
\hline$b_{0}$ & $\begin{array}{c}4.63 \\
(135.33)^{*}\end{array}$ & - & $\begin{array}{c}30.80 \\
(1214.18)^{*}\end{array}$ & - & $\begin{array}{c}7.90 \\
(149.16)^{*}\end{array}$ & - & $\begin{array}{c}4.52 \\
(576.75)^{*}\end{array}$ & - & $\begin{array}{c}1.08 \\
(163.34)^{*}\end{array}$ & - & $\begin{array}{c}2.22 \\
(389.28)^{*}\end{array}$ & - & $\begin{array}{c}0.51 \\
(190.33)^{*}\end{array}$ & - \\
\hline$b_{1}$ & $\begin{array}{c}1.75 \\
(41.70)^{*}\end{array}$ & $1739.19 *$ & $\begin{array}{c}5.48 \\
(176.57)^{*}\end{array}$ & $31179.23 *$ & $\begin{array}{c}2.02 \\
(31.20)^{*}\end{array}$ & $973.77 *$ & $\begin{array}{c}3.15 \\
(328.46)^{*}\end{array}$ & $107888.8^{*}$ & $\begin{array}{c}0.43 \\
(53.58)^{*}\end{array}$ & $2870.96 *$ & $\begin{array}{c}1.81 \\
(259.87)^{*}\end{array}$ & $67536.66^{*}$ & $\begin{array}{c}0.29 \\
(89.18)^{*}\end{array}$ & $7953.58 *$ \\
\hline$b_{11}$ & $\begin{array}{c}0.50 \\
(13.84)^{*}\end{array}$ & $191.65^{*}$ & $\begin{array}{c}-0.75 \\
(-28.04)^{*}\end{array}$ & $786.66^{*}$ & $\begin{array}{c}1.33 \\
(23.82)^{*}\end{array}$ & $567.55^{*}$ & $\begin{array}{c}-1.65 \\
(-198.53)^{*}\end{array}$ & $39415.0 *$ & $\begin{array}{c}-0.48 \\
(-68.55)^{*}\end{array}$ & $4699.19 *$ & $\begin{array}{c}-0.78 \\
(-129.32) *\end{array}$ & $16725.47 *$ & $\begin{array}{c}-0.22 \\
(-75.87)^{*}\end{array}$ & $5756.51 *$ \\
\hline$b_{2}$ & $\begin{array}{c}-0.31 \\
(-7.44)^{*}\end{array}$ & $55.43^{*}$ & $\begin{array}{c}9.48 \\
(305.19)^{*}\end{array}$ & $93146.29 *$ & $\begin{array}{c}0.10 \\
(1.67)\end{array}$ & 2.80 & $\begin{array}{c}-1.26 \\
(-131.18)^{*}\end{array}$ & $17208.8^{*}$ & $\begin{array}{c}-0.09 \\
(-12.06)^{*}\end{array}$ & $145.50 *$ & $\begin{array}{c}-0.87 \\
(-125.61)^{*}\end{array}$ & $15779.58 *$ & $\begin{array}{c}-0.08 \\
(-25.42)^{*}\end{array}$ & $646.17^{*}$ \\
\hline$b_{22}$ & $\begin{array}{c}-0.73 \\
(-19.97)^{*}\end{array}$ & $399.11 *$ & $\begin{array}{c}-1.96 \\
(-73.09)^{*}\end{array}$ & $5343.47 *$ & $\begin{array}{c}-1.78 \\
(-31.77)^{*}\end{array}$ & $1009.66^{*}$ & $\begin{array}{c}-0.23 \\
(-28.21)^{*}\end{array}$ & $796.0 *$ & $\begin{array}{c}0.31 \\
(44.04)^{*}\end{array}$ & $1939.53 *$ & $\begin{array}{c}-0.16 \\
(-26.72)^{*}\end{array}$ & $714.35^{*}$ & $\begin{array}{c}0.16 \\
(54.48)^{*}\end{array}$ & $2968.46^{*}$ \\
\hline$b_{12}$ & $\begin{array}{c}-0.38 \\
(-0.02)\end{array}$ & 0.15 & $\begin{array}{c}-2.81 \\
(73.83)^{*}\end{array}$ & $5452.13^{*}$ & $\begin{array}{c}-1.66 \\
(-21.00)^{*}\end{array}$ & $441.28 *$ & $\begin{array}{c}-2.13 \\
(-181.23)^{*}\end{array}$ & $32845.2^{*}$ & $\begin{array}{c}-0.32 \\
(-32.16)^{*}\end{array}$ & $1034.43 *$ & $\begin{array}{c}-1.39 \\
(-162.08)^{*}\end{array}$ & $26271.43 *$ & $\begin{array}{c}-0.19 \\
(-48.10)^{*}\end{array}$ & $2314.44^{*}$ \\
\hline$b_{122}$ & $\begin{array}{c}-1.42 \\
(-31.96)^{*}\end{array}$ & $1021.56^{*}$ & $\begin{array}{c}-1.01 \\
(30.81)^{*}\end{array}$ & $949.36^{*}$ & $\begin{array}{c}-0.20 \\
(-3.01)^{*}\end{array}$ & $9.06 *$ & $\begin{array}{c}-0.40 \\
(-39.74)^{*}\end{array}$ & $1579.4^{*}$ & $\begin{array}{c}0.52 \\
(60.64)^{*}\end{array}$ & $3678.18 *$ & $\begin{array}{c}-0.21 \\
(-28.56)^{*}\end{array}$ & $815.69 *$ & $\begin{array}{c}0.27 \\
(76.28)^{*}\end{array}$ & $5819.55^{*}$ \\
\hline$b_{112}$ & $\begin{array}{c}-8.22 \\
(-0.37)^{*}\end{array}$ & $67.64 *$ & $\begin{array}{c}0.86 \\
(26.32)^{*}\end{array}$ & $692.97 *$ & $\begin{array}{c}3.54 \\
(51.54)^{*}\end{array}$ & $2656.49 *$ & $\begin{array}{c}0.80 \\
(78.61)^{*}\end{array}$ & $6180.9 *$ & $\begin{array}{c}0.09 \\
(11.41)^{*}\end{array}$ & $130.35^{*}$ & $\begin{array}{c}0.55 \\
(75.36)^{*}\end{array}$ & $5679.67 *$ & $\begin{array}{c}0.07 \\
(20.55)^{*}\end{array}$ & $422.26 *$ \\
\hline$b_{1122}$ & $\begin{array}{c}0.86 \\
(22.33)^{*}\end{array}$ & $498.91 *$ & $\begin{array}{c}0.97 \\
(34.06)^{*}\end{array}$ & $1160.35^{*}$ & $\begin{array}{c}-1.33 \\
(22.45)^{*}\end{array}$ & $504.30 *$ & $\begin{array}{c}0.27 \\
(31.40)^{*}\end{array}$ & $986.5 *$ & $\begin{array}{c}-0.24 \\
(-32.31)^{*}\end{array}$ & $1043.92 *$ & $\begin{array}{c}0.087 \\
(13.56)^{*}\end{array}$ & $183.99 *$ & $\begin{array}{c}-0.14 \\
(-44.97)^{*}\end{array}$ & $2019.32 *$ \\
\hline $\mathrm{R}^{2}$ & 0.9954 & & 0.9998 & & 0.9970 & & 0.9999 & & 0.9988 & & 0.9998 & & 0.9993 & \\
\hline$R^{2}$ adjusted & 0.9934 & & 0.9998 & & 0.9957 & & 0.9998 & & 0.9983 & & 0.9998 & & 0.9990 & \\
\hline
\end{tabular}

*Significant $t$-test for $\alpha=0.05\left[\mathrm{t}_{(1,18)}\right]$ and $\mathrm{F}$ for $\alpha=0.05\left[\mathrm{~F}_{(1,18)}\right]$. EtOH: Ethanol; DR: dry residue; TPC: Total Polyphenol Content; EE: extractive efficiency; GA: Gallic acid; EA: Ellagic acid. 

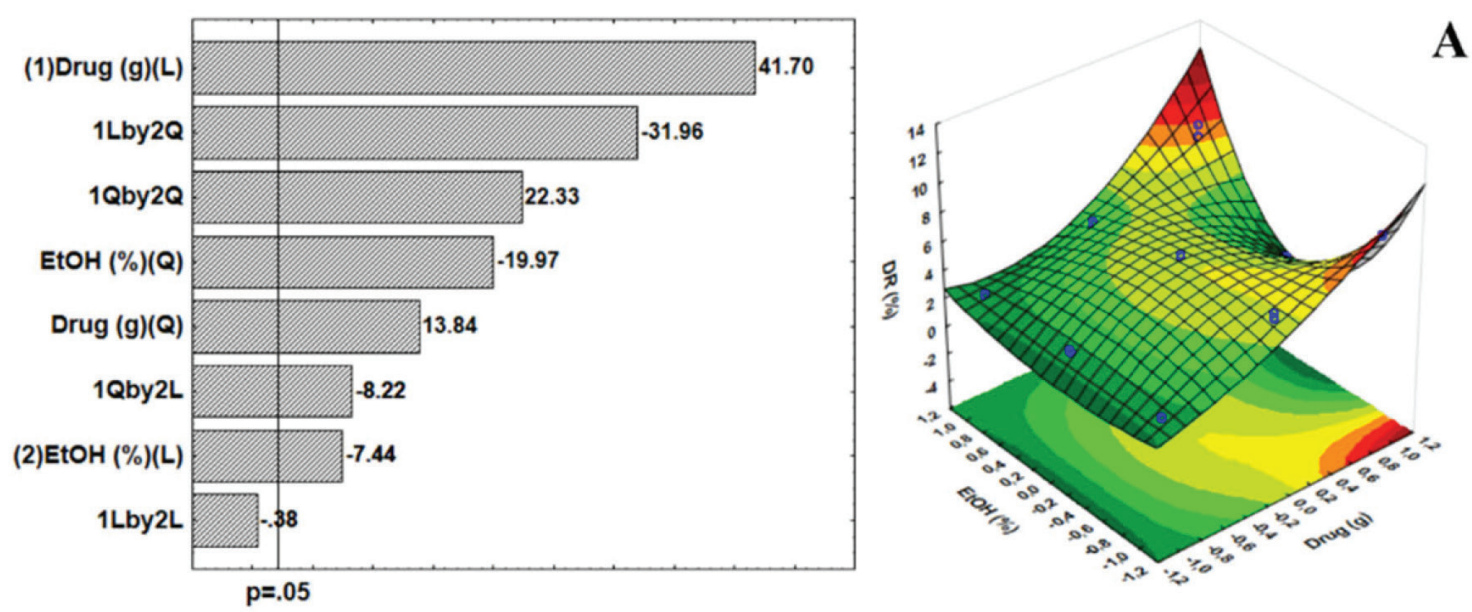

A
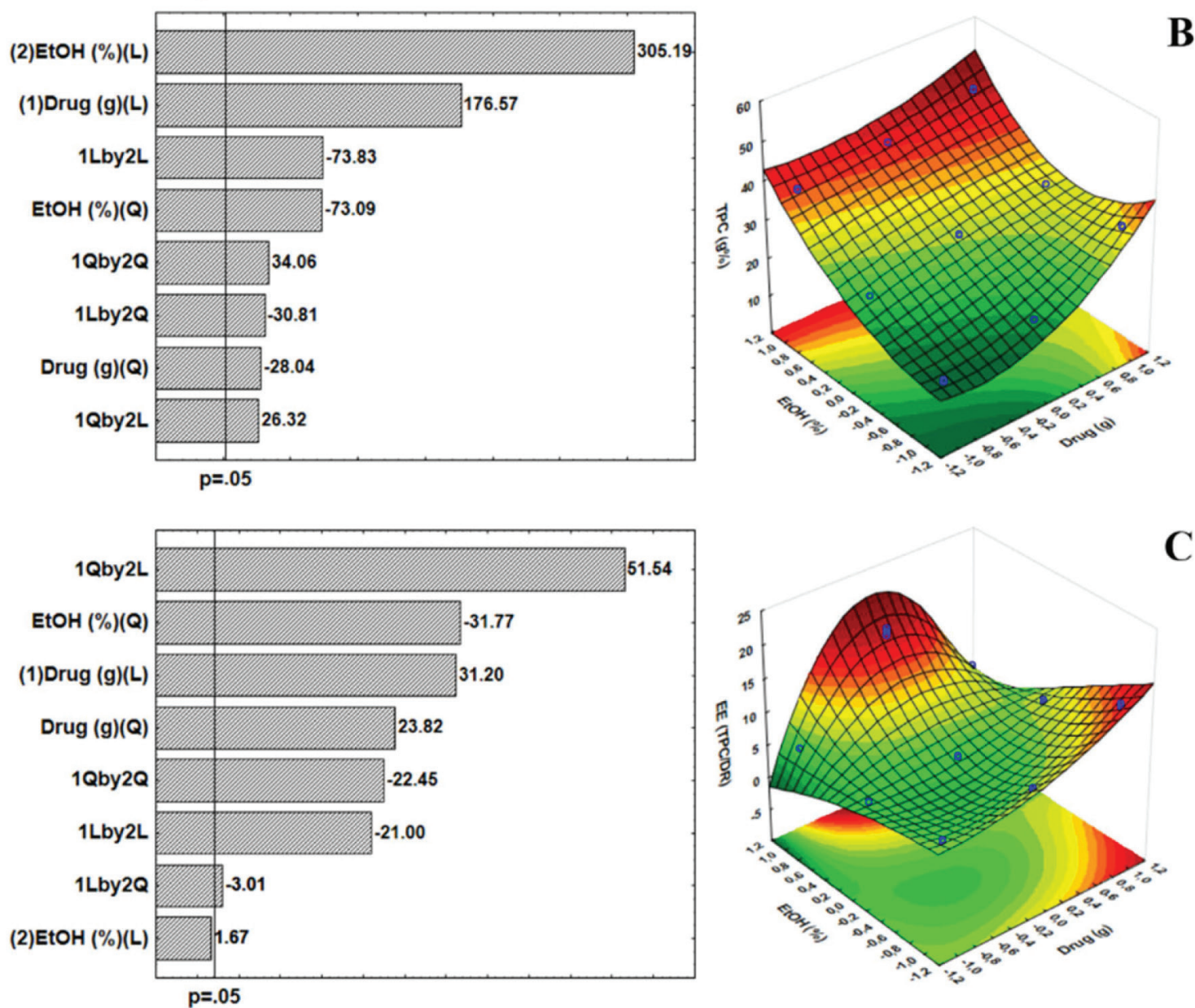

Figure 1. Pareto Chart and Response Surface for results of Dry Residue (A), Total Polyphenol Content (B) and Efficiency Extraction (C)

In order to evaluate the quality of extractable material was determinate the Extraction Efficiency (EE). The yield of compound of interest (TPC) by dried residue plays a pivotal role in the strategy for the development of phytopharmaceutical products, especially for solid dosage forms. ${ }^{11,20}$ Thus, the factor drug amount showed a positive linear influence on the EE responses, besides the positive influence observed by the interaction between drug quantity and ethanol concentration, and the ethanol effect depends on the level assumed by the drug factor, which has a described influence by the quadratic term (Figure 1C). Investigation of interactions is important since the optimal values established for a given factor may depend on the levels of the other factors employed, in this case, the ethanol concentration is linearly related to the response when the amount of drug is at its appropriate level, reflected in curvature as described in the quadratic term.

When using hydroalcoholic mixtures (water and ethanol) it is possible to extract soluble substances in both solvents; however, polyphenols are more soluble in polar organic solvents, indicating that the use of $80 \%$ ethanol has a better TPC response (45.32 $\mathrm{g} \%$ ). The effects of the ethanol ratio may differ depending on the plant species; may be influenced by the chemical constitution of the extractive solution as to the presence of glycosylated or non-glycosylated constituents, affecting the solubility in certain solvents or mixture; and affect the extraction yield. ${ }^{23,24}$ 
The yield of an extractive process is dependent on the type of solvents (different polarities), extraction time, temperature and drug: solvent ratio, as well as the composition and characteristics of the samples. Regarding the solubility of polyphenols, extraction is measured by the nature of the sample as well as the polarity of the solvents used. ${ }^{25}$ The literature reports that solvents such as acetone, ethanol and methanol, or their combinations often with water, ${ }^{19,26}$ have been widely used to extract polyphenols from plant matrices. Ethanol, used in different proportions in this study, is effective for extraction of polyphenols, and is less toxic for use. ${ }^{27}$ As for the method, in turbolysis extraction occurs simultaneously with particle size reduction due to the applied shear forces. The reduction of particle size and the disruption of cells favor the process, resulting in shorter extraction time and near exhaustion of the drug. ${ }^{26}$
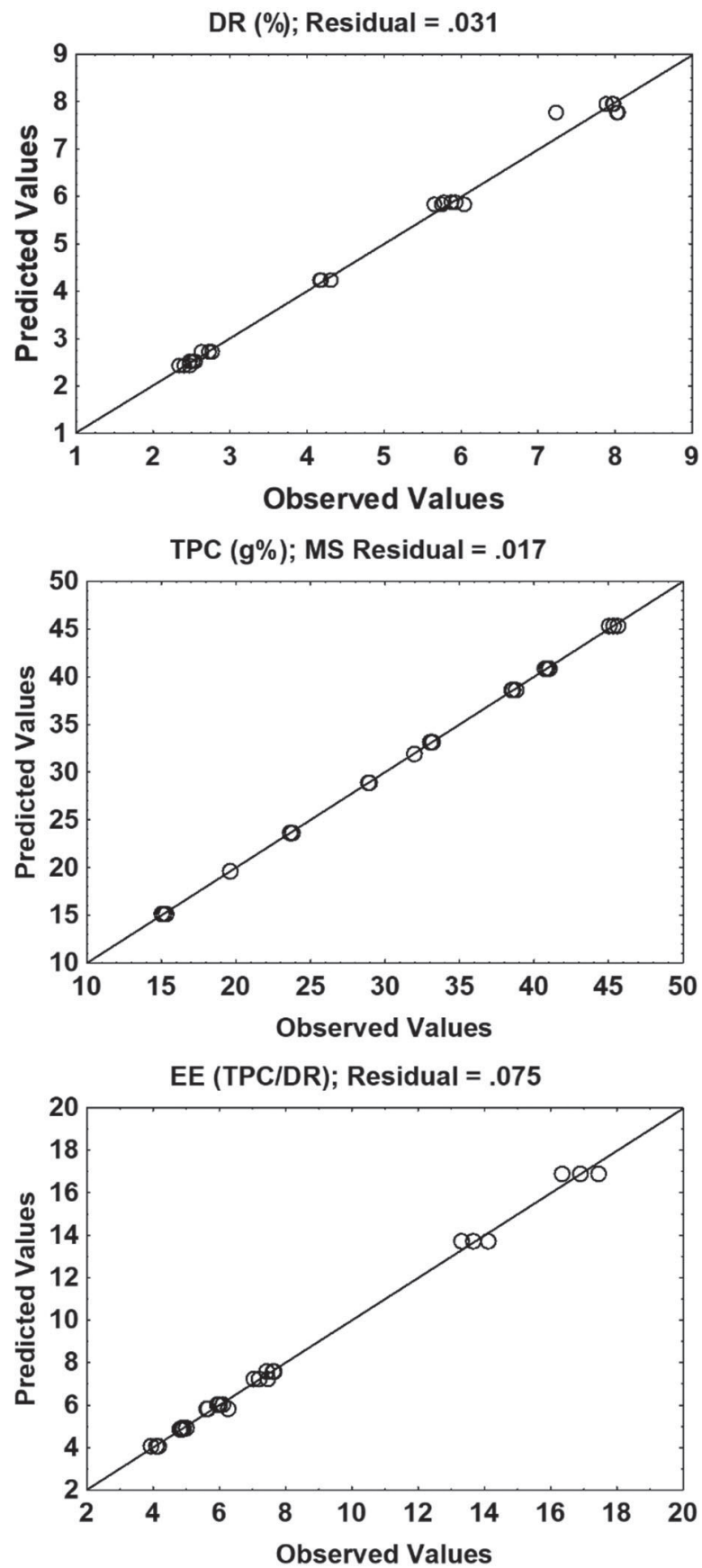

The normality of the data can be verified through the residues. In this case, the normal probability plot is used to assess whether or not the data set is normally distributed. The residual is the difference between the observed value and the predicted value of the regression. The Figure 2 shows the graph of normal probability of residual values. It is possible to observe that the experimental data are reasonably aligned, suggesting normal distribution. In addition, such results can also be displayed with the help of a histogram, which are almost symmetrical (bell-shaped, that is, errors are normally distributed with a mean zero).

\section{Markers content by HPLC and Efficiency of Extraction}

Three-dimensional response surface plots at the Figure 3A-B show that the two responses (ellagic acid and gallic acid content,
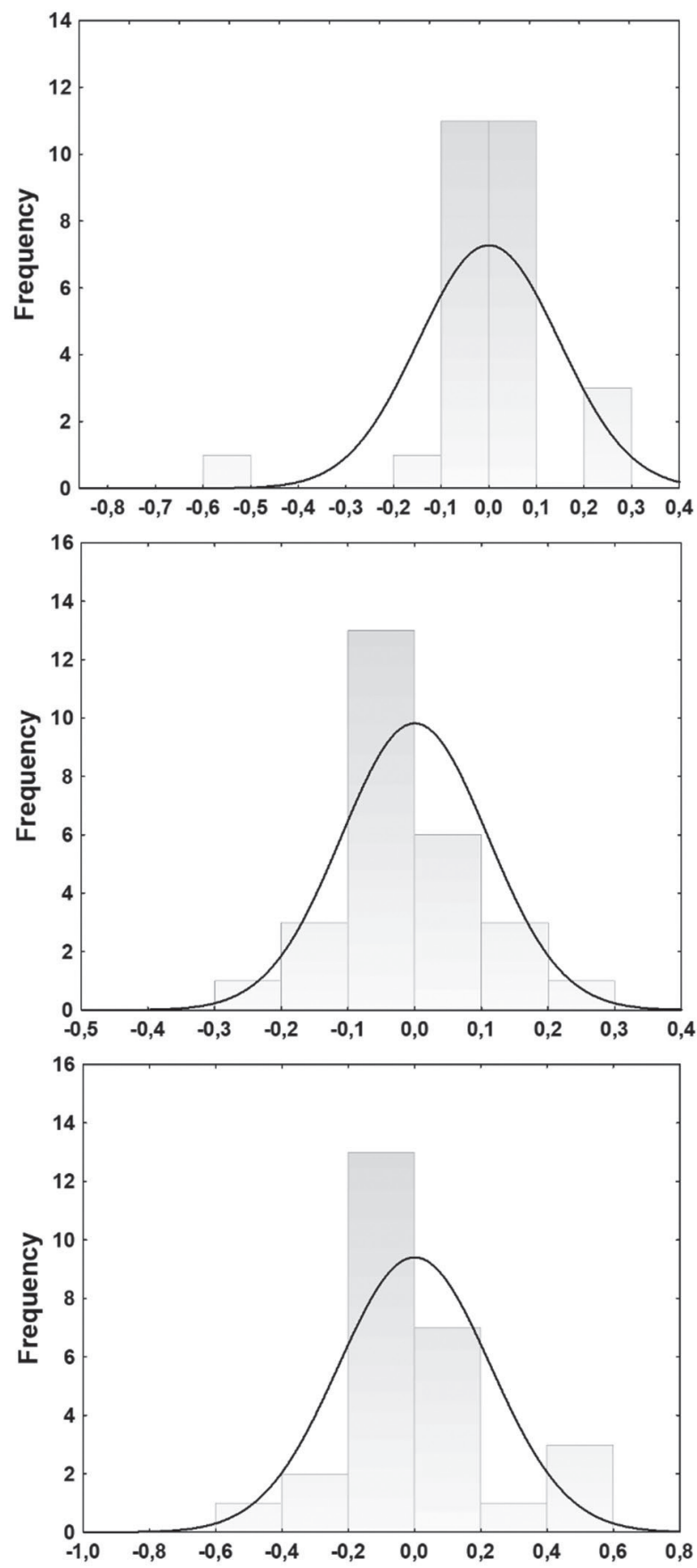

Figure 2. The normal probability plot of standardized residuals and the histogram of standardized residuals (dry residue, total polyphenol content and extraction efficiency) 
calculated by HPLC) of this analysis has similar tendency with respect to ethanol concentration. At first, increasing the proportion of ethanol does not increase ellagic acid and gallic acid extraction performance. In the study of optimizing the extraction of polyphenols from Sideritis montana L., it was observed that $60 \%$ ethanol concentration presents optimal values of TPC. ${ }^{23}$

Although not statistically important for the ethanol concentration considering the markers of the species, it is necessary to consider the influence on the TPC and DR response. The use of water and ethanol improve the extraction of polyphenols from plant material, so that water swells the plant material, allowing ethanol to penetrate the matrix more easily and improving compound transfer. ${ }^{28}$

In general, the contents of ellagic acid and gallic acid increased with the amount of drug. When looking at the Pareto chart (data no shown), the amount of drug has a positive influence on the responses in the linear term $(+328.46$ and +259.87 , respectively for ellagic acid and gallic acid) and in the quadratic term the influence is negative giving to a kind of valley almost perpendicular to the response surface of both markers.

In the Figure 4, the residues were distributed in an almost normal distribution and the splashes were dispersed in the bar, corresponding to a normal distribution with an average of zero. This indicates that the residuals of the random variable obey a normal distribution and the regression model passed the significance test. Therefore, mathematical models can be used to assess the relationship between the factors studied and the responses obtained.

Considering the results obtained by the type $3^{2}$ factorial design, experimental validation by performing an additional experiment is not necessary because the complete model is statistically validated by analysis of variance, calculation of the multiple correlation coefficient and estimate of lack of fit, as mentioned previously in accordance with the criteria adopted in Table 1, established by Wherlé. ${ }^{16}$

\section{Desirability profiles}

In addition to the use of response surface methodology, another tool used to optimize various responses is the desirability method. The tool is based on the idea that the quality of a product or process that has many features is completely unacceptable if one of them is outside a "desirable" limit. Thus, the objective is to find conditions that ensure compliance with the criteria of all the answers involved
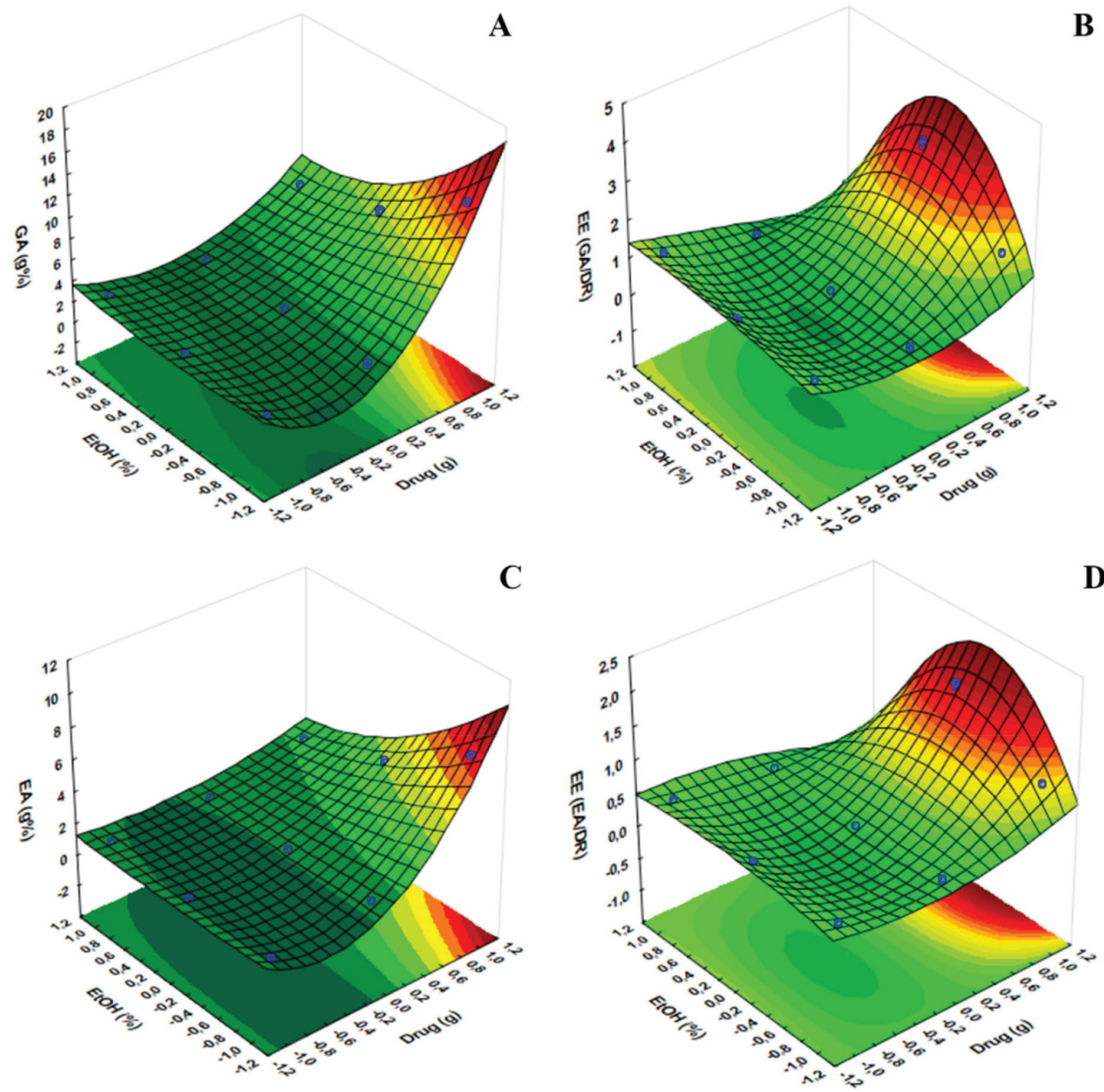

Figure 3. Response Surface for results of Gallic acid (A), Efficiency extraction of Gallic (B), Ellagic acid (C) and Efficiency extraction of Ellagic acid (D) 

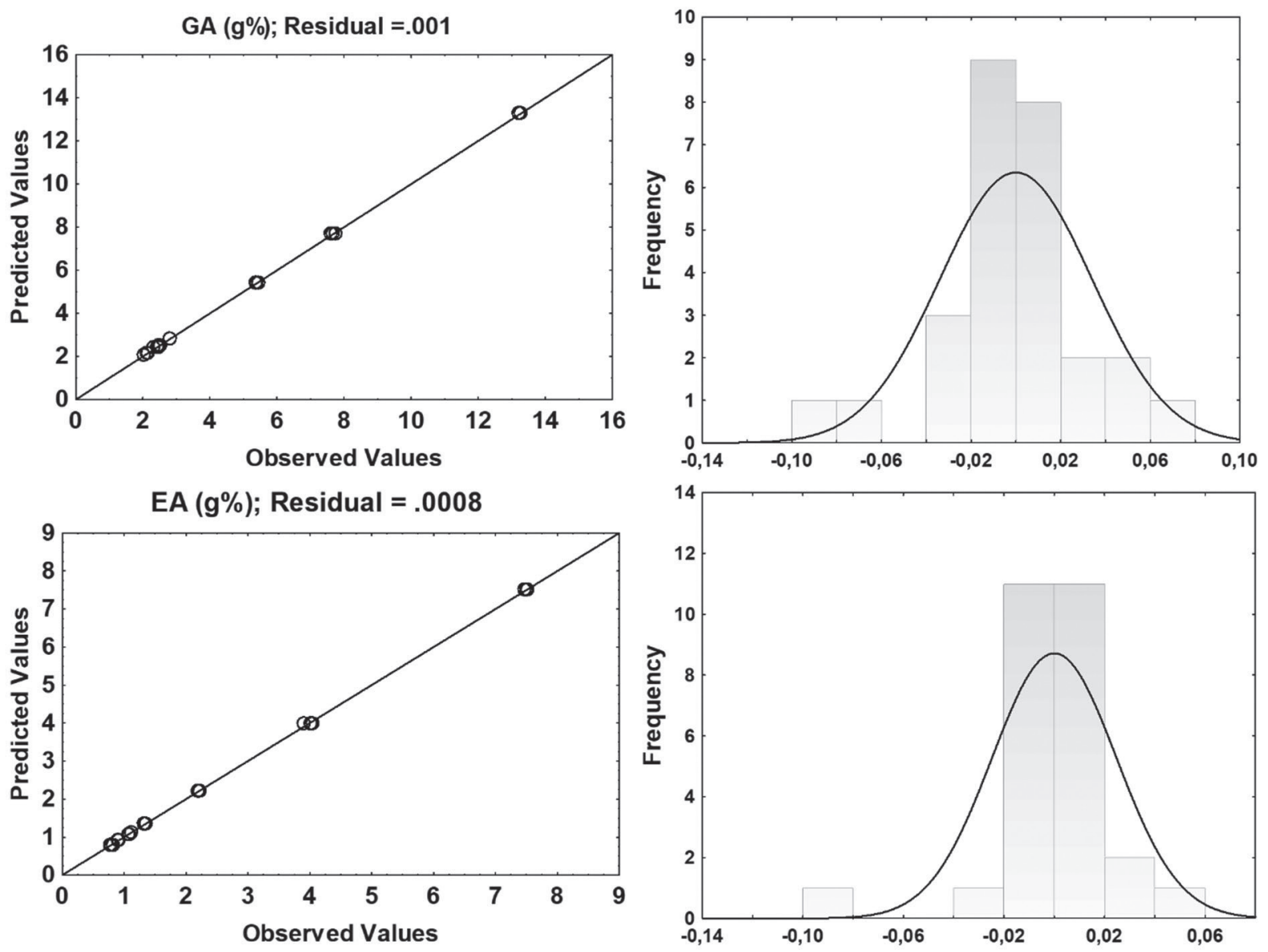

Figure 4. The normal probability plot of standardized residuals and the histogram of standardized residuals (gallic acid - GA and ellagic acid - EA content by $H P L C)$

and, at the same time, provide the best value in the joint answer, this value being the most desirable. It is first necessary to convert the response into individual desirability ranging from 0 to 1 (less convenience for greater convenience).$^{29}$ The desirability data obtained from all responses are shown with the respective confidence interval values are shown in Table 4.

When looking at Figures 5 and 6, it appears that the first two profiles are related to the variation of responses (DR, TPC, EE (TPC/DR), contents of GA and EA, and EE of GA and EA) with each factor, keeping the others fixed at the critical value. The third profile shows the desirability of the responses, the range of the acceptable desirability response $(0 \leq \mathrm{di} \leq 1)$. The higher the $\mathrm{D}$ value, the better the method response, the greater the sensitivity, and the maximum D value is the optimized system condition. The last two profiles show the individual desirability for each factor and overall desirability. The vertical red lines in the graphs correspond to the optimal values of the studied parameters and are located exactly at the central points. It was not possible to reach a maximum point, so the parameters cannot be analyzed univariate, so we sought a common "point", where all the parameters investigated obtained, in a multivariate and within the studied range, the best responses.

\section{CONCLUSIONS}

Response Surface Methodology (RSM) was successfully used to describe the experimental space for data obtained in this study. Based on these results, with the analysis of RSM and desirability, the optimum conditions to obtain acceptable responses to produce

Table 4. Response obtained for desirability analysis from factorial design

\begin{tabular}{|c|c|c|c|c|c|}
\hline Response & Level of Drug & Level of EtOH & Desirability value & $\begin{array}{l}\text { Predict Value of } \\
\text { Response }\end{array}$ & $\begin{array}{c}\text { Confidence Interval of } \\
\text { Response }\end{array}$ \\
\hline $\mathrm{DR}(\%)$ & 1 & -1 & 0.9824 & 7.95 & $7.73-8.16$ \\
\hline TPC $(\mathrm{g} \%)$ & 1 & 1 & 0.9907 & 45.31 & $45.15-45.47$ \\
\hline $\mathrm{EE}(\mathrm{TPC} / \mathrm{DR})$ & 0 & 1 & 0.9593 & 16.90 & $16.57-17.24$ \\
\hline $\mathrm{GA}(\mathrm{g} \%)$ & 1 & -1 & 0.9979 & 13.26 & $13.21-13.31$ \\
\hline EA $(g \%)$ & 1 & -1 & 0.9975 & 7.49 & $7.46-7.53$ \\
\hline $\mathrm{EE}(\mathrm{GA} / \mathrm{DR})$ & 1 & 0 & 0.9689 & 3.17 & $3.13-3.21$ \\
\hline $\mathrm{EE}(\mathrm{EA} / \mathrm{DR})$ & 1 & 0 & 1.0000 & 1.67 & $1.65-1.69$ \\
\hline
\end{tabular}

EtOH: Ethanol; DR: dry residue; TPC: Total Polyphenol Content; EE: extractive efficiency; EA: Ellagic acid; GA: Gallic acid. 

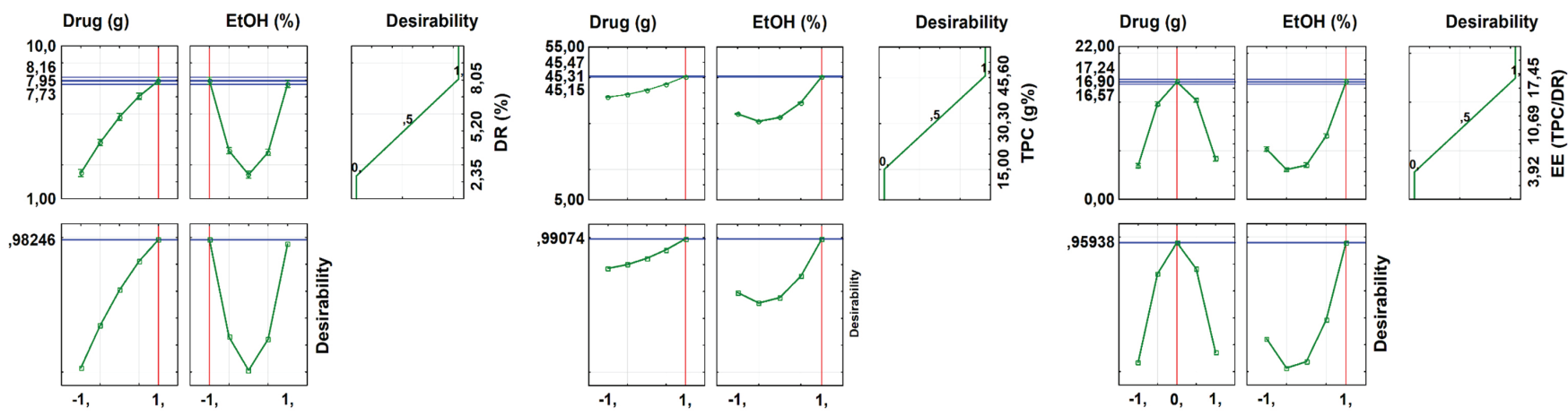

Figure 5. Profile of predicted/optimized values and desirability for Dry residue, Total Polyphenol Content and Efficiency extraction
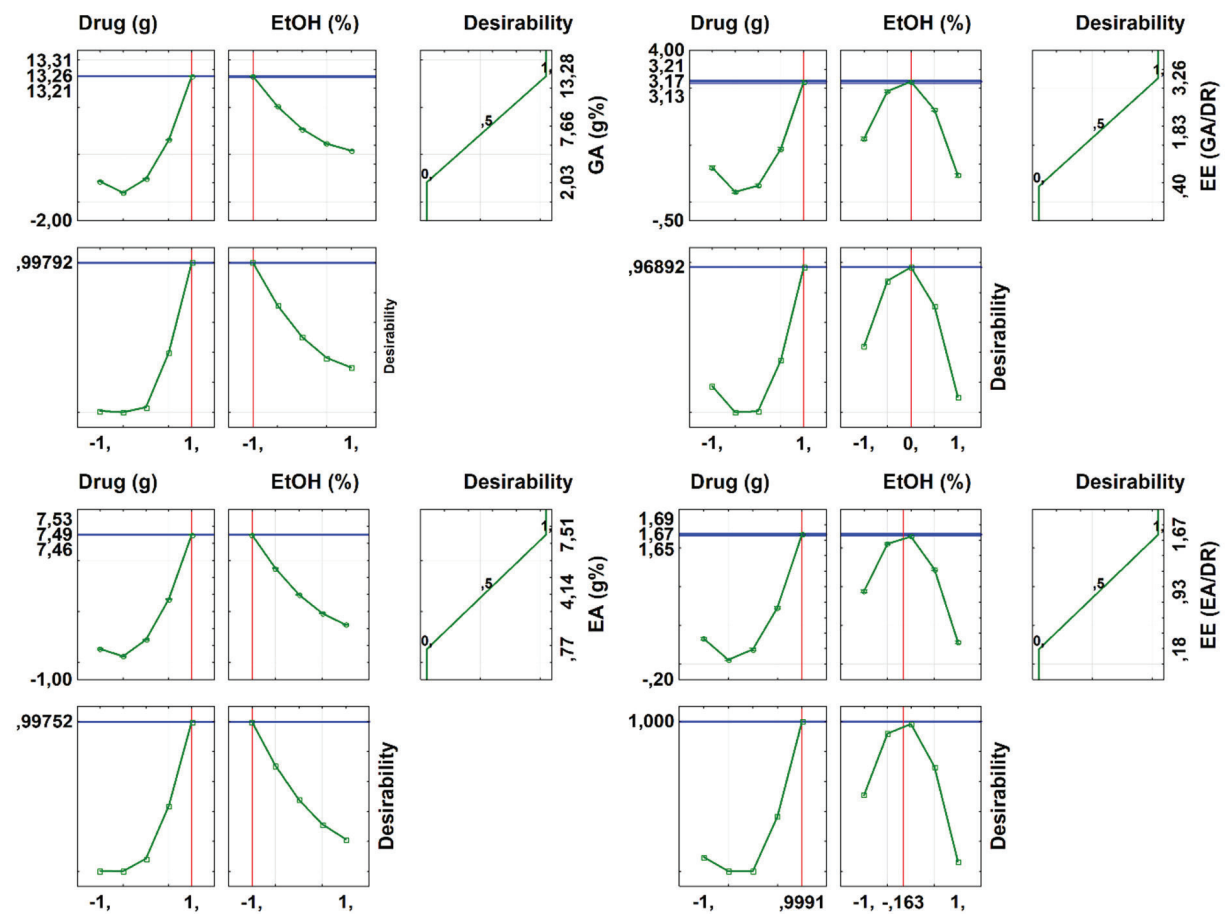

Figure 6. Profile of predicted/optimized values and desirability for Gallic acid and Ellagic acid content and Efficiency extraction of markers

extractive solutions of Libidibia ferrea pods were employing $15 \mathrm{~g}$ of the amount of drug and ethanol $40 \%$ (v/v). Standardization of extractive solutions, using factorial design, can be employed as a strategy to obtain reproducible products with appropriate values such as DR and content of markers, influential characteristics in subsequent processes.

\section{ACKNOWLEDGMENT}

This work was supported by the CNPq (405297/2018-1 and 307110/2018-4), FACEPE (APQ04934.03/14) and CAPES for the scholarship PNPD (88882.306311/2018-01).

\section{REFERENCES}

1. Flora do Brasil, Fabaceae in Jardim Botânico do Rio de Janeiro, available at http://floradobrasil.jbrj.gov.br/reflora/floradobrasil/ FB109828, accessed in April 2020.

2. Albuquerque, U. P.; Medeiros, P. M.; Almeida, A. L. S.; Monteiro, J. M.; Lins Neto, E. M. F.; Melo, J. G.; Santos, J. P.; J. Ethnopharmacol. 2007, $114,325$.

3. Ferreira, M. R. A.; Soares, L. A. L.; J. Med. Plants Res. 2015, 9, 140.

4. Ferreira, M. R. A.; Santiago, R. R.; Langassner, S. M. Z.; Mello, J. C. P.; Svidzinsk, T. I. E.; Soares, L. A. L.; J. Med. Plants Res. 2013, 7, 3008.
5. Araújo, A. A.; Soares, L. A. L.; Ferreira, M. R. A.; Souza Neto, M. A.; Silva, G. R.; Araújo Junior, R. F.; Guerra, G. C. B.; Melo, M. C. N.; J. Ethnopharmacol. 2014, 156, 88.

6. Guerra, A. C. V. A.; Soares, L. A. L.; Ferreira, M. R. A.; Araujo, A. A.; Rocha, H. A. O.; Medeiros, J. S.; Cavalcante, R. S.; Araujo Junior, R. F.; Biomed. Pharmacother. 2017, 92, 696.

7. Falcao, T. R.; Araujo, A. A.; Soares, L. A. L.; Farias, I. B.; Viturino, W. A.; Ferreira, M. R. A.; Araújo Junior, R. F.; Medeiros, J. S.; Guerra, G. C. B.; Lopes, M. L. D. S.; Evidence-Based Complementary Altern. Med. 2019a, 2019, 1.

8. Falcao, T. R.; Rodrigues, C. A. O.; Araujo, A. A.; Medeiros, C. A. C. X.; Ferreira, M. R. A.; Soares, L. A. L.; Vasconcelos, R. C.; Araújo Junior, R. F.; Lopes, M. L. D. S.; Guerra, G. C. B.; BMC Complementary Altern. Med. 2019b, 19, 1.

9. Galvão, M. A. M.; Arruda, A. O.; Bezerra, I. C. F.; Ferreira, M. R. A.; Soares, L. A. L.; Braz. Arch. Biol. Technol. 2018, 61, 1.

10. Ferreira, M. R. A.; Fernandes, M. T. M.; Viturino, W. A.; Bezerra, I. C. F.; De Souza, T. P.; Pimentel, M. F.; Soares, L. A. L.; Pharmacogn. Mag. 2016, 12, 285.

11. Cunha, F. P.; Costa, L. J. L.; Fernandes, A. J. D.; De Souza, T. P.; Soares, L. A. L.; Braz. Arch. Biol. Technol. 2009, 52, 647.

12. Sarfarazi, M.; Jafari, S. M.; Rajabzadeh, G.; Food Anal. Met. 2015, 8, 2273. 
13. Zielinski, A. A. F.; Haminiuk, C. W. I.; Beta, T.; LWT--Food Sci. Technol. 2016, 65, 897.

14. Los, F. G. B.; Zielinski, A. A. F.; Wojeicchowski, J. P.; Nogueira, A.; Demiate, I. M.; Food Anal. Met. 2019, 12, 148.

15. Prgomet, I.; Berta, G.; Domínguez-Perles, R.; Pascual-Seva, N.; Barros, A. I. R. N. A.; Food Anal. Met. 2019, 12, 2009.

16. Wehrlé, P.; Nobelis, P.; Cuiné, A.; Stamm, A.; Drug Dev. Ind. Pharm. 1993, 19, 1673.

17. Myers, R. H.; Montgomery, D. C.; Anderson-Cook, C. M.; Response Surface Methodology: Process and Product Optimization Using Designed Experiments, $4^{\text {th }}$ ed., Wiley: New York, 2016.

18. Ramos, R. T. M.; Bezerra, I. C. F.; Ferreira, M. R. A.; Soares, L. A. L.; Pharmacogn. Res. 2017, 9, 253.

19. Bezerra, I. C. F.; Ramos, R. T. M.; Ferreira, M. R. A.; Soares, L. A. L.; Rev. Bras. Farmacogn. 2018, 28, 92.

20. Soares, L. A. L.; González Ortega, G.; Petrovick, P. R.; Schmidt, P. C.; AAPSPharmSciTech 2005, 6, 368.
21. Bezerra, M. A.; Santelli, R. E.; Oliveira, E. P.; Villar, L. S.; Escaleira, L. A.; Talanta 2008, 76, 965.

23. Bilgin, M.; Elhussein, E. A. A.; Özyürek, M.; Güçlü, K.; Şahin, S.; J. Pharm. Biomed. Anal. 2018, 158, 137.

24. Rivera-Mondragón, A.; Broeckx, G.; Bijttebier, S.; Naessens, T.; Fransen, E.; Kiekens, F.; Caballero-George, C.; Heyden, Y. V.; Apers, S.; Pieters, L.; Foubert, K.; Sci. Rep. 2019, 1, 2028.

25. Truong, D.-H.; Nguyen, D. H.; Ta, N. T. A.; Bui, A. V.; Do, T. H.; Nguyen, H. C.; J. Food Qual. 2019, 2019, 9.

26. Mojzer, E. B.; Hrnčič, K. M.; Škerget, M.; Knez, Z.; Bren, U.; Molecules 2016, 21, 901.

27. Bamba, B. S. B.; Shi, J.; Tranchant, C. C.; Xue, S. J.; Forney, C. F.; Lim, L-T.; Molecules 2018, 23, 1685.

28. Hosseini, H.; Bolourian, S.; Hamgini, E. Y.; Mahababadi, E. G.; J. Food Process. Preserv. 2018, 42, e13778.

29. Candioti, L. V.; De Zan, M. M.; Cámara, M. S.; Goicoechea, H. C.; Talanta 2014, 124, 123. 